\title{
Polypropylene obtained through Zeolite Supported Catalysts
}

\author{
Queli C. Bastos, Maria de Fátima V. Marques \\ Instituto de Macromoléculas Professora Eloisa Mano, UFRJ
}

\begin{abstract}
Propylene polymerizations were carried out with $\phi_{2} \mathrm{C}(\mathrm{Flu})(\mathrm{Cp}) \mathrm{ZrCl}_{2}$ and $\mathrm{SiMe}_{2}(\mathrm{Ind})_{2} \mathrm{ZrCl}_{2}$ catalysts supported on silica, zeolite sodic mordenite $(\mathrm{NaM})$ and acid mordenite (HM). The polymerizations were performed at different temperatures and varying aluminium/zirconium molar ratios $([\mathrm{Al}] /[\mathrm{Zr}])$. The effect of these reaction parameters on the catalyst activity was investigated using a proposed statistical experimental planning. In the case of $\mathrm{f}_{2} \mathrm{C}(\mathrm{Flu})(\mathrm{Cp}) \mathrm{ZrCl}_{2}$, $\mathrm{SiO}_{2}$ and $\mathrm{NaM}$ were used as support and the catalyst performance evaluated using toluene and pentane as polymerization solvent. The molecular weight, molecular weight distribution, melting point and crystallinity of the polymers were examined. The results indicate very high activities for the syndiospecific heterogeneous system. Also, the polymers obtained had superior Mw and stereoregularity.
\end{abstract}

Keywords: Isotactic polypropylene, syndiotactic polypropylene, metallocene catalyst, supports.

\section{Introduction}

Since the discovery of highly active metallocene catalysts by Kaminsky and Sinn ${ }^{[1]}$ many efforts have been made to investigate catalyst systems based on Group 4 metallocene complexes. In combination with methylaluminoxane (MAO) as cocatalyst, these metallocene complexes allow unprecedented control on the polyolefin structure due to catalyst design.

Although these catalyst systems offer the capability for the synthesis of polymeric materials with unique properties, technical problems due to their homogeneous character are arising. Major disadvantages of the homogeneous catalysts are both the lack of morphology control and reactor fouling. Supported catalysts allow the control of polymer particle shape, and also they can be employed in cheaper bulk propylene or gas-phase processes. Moreover, they can allow the use of less MAO, whilst still offering facile control of polymer properties through ligand variation ${ }^{[2]}$. Several scientific papers and patents report the use of $\mathrm{SiO}_{2}, \mathrm{Al}_{2} \mathrm{O}_{3}$, $\mathrm{MgCl}_{2}$, zeolites and polymers as suitable carriers.

The development of effective supported metallocene catalysts for olefin polymerization continues to attract attention ${ }^{[3]}$.

Considering that syndiotactic polypropylene (s-PP) exhibits excellent mechanical and optical properties, and that this type of metallocene system promotes propylene polymerization leading to polymers with interesting characteristics, this system has been studied for some researchers ${ }^{[4,5]}$. As demonstrated by Ewen et al. ${ }^{[6]}$, Cssymmetric catalysts promote highly syndiospecific propylene polymerization by the enantiomorphic-site control mechanism via the primary insertion mode. On the other hand, the $\mathrm{VCl}_{4} / \mathrm{AlEtCl}_{2}$ (conventional Ziegler-Natta catalyst) produces less stereoregular s-PP, due to chainend control via the secondary insertion mode and also, with very low activities. It is expected a strong difference in sPP microstructure, and therefore, polymer property obtained by both type of catalysts.

Thus, the objective of this work is to investigate the performance of $\phi_{2} \mathrm{C}(\mathrm{Flu})(\mathrm{Cp}) \mathrm{ZrCl}_{2} / \mathrm{MAO}$ and $\mathrm{SiMe}_{2}(\mathrm{Ind})_{2}$ $\mathrm{ZrCl}_{2} / \mathrm{MAO}$ catalysts, evaluating them in the homogeneous and supported systems for propylene polymerization.

This work consists in two experimental parts. The first one deals with propylene polymerization using syndiospecific metallocene supported on $\mathrm{SiO}_{2}$ and sodic modernite $(\mathrm{NaM})$ using toluene and pentane as polymerization solvents.

In the second part, homogeneous and heterogeneous polymerizations were carried out with syndiospecific and isospecific metallocenes supported on acid mordenite. The heterogeneous polymerizations were performed in hexane/ TIBA as diluent and at different temperatures and $\mathrm{Al} / \mathrm{Zr}$ molar ratios. The effect of these reactions parameters on the catalyst activity was investigated using a proposed statistical experimental planning model. The molecular weight, polydispersity, melting temperature and morphology of the obtained polymers have been investigated.

\section{Experimental}

\section{General}

All operations were performed under nitrogen by using conventional Schlenk techniques. MAO 10\% solution in toluene was kindly supplied by Compton (Germany) and used without purification. Propylene and nitrogen supplied by White Martins S.A. (Brazil) were treated through columns packed with $3 \AA$ molecular sieve and copper catalyst. Toluene was distilled over sodium/benzophenone

Autor para correspondência: Maria de Fátima V. Marques, Instituto de Macromoléculas Professora Eloisa Mano, UFRJ, Caixa Postal 68525, CEP: 21941590, Rio de Janeiro, RJ, Brasil.E-mail: fmarques@ima.ufrj.br 
under nitrogen. Dry hexane kindly supplied by Petroflex, Brazil, was nitrogen bubbled for $1 \mathrm{hr}$. and used as received and pentane was distilled under phosphorous V oxide. Triisobutylaluminium (TIBA) from Crompton, was diluted at 0.025M in hexane. $\mathrm{SiO}_{2}$ (Sylopol 928, from Grace Davison, USA) and both zeolite NaM (CBV 10A) and zeolite HM (CBV 90A) were donated by PQ Corporation, USA.

\section{Catalysts}

The complex $\phi_{2} \mathrm{C}(\mathrm{Flu})(\mathrm{Cp}) \mathrm{ZrCl}_{2}$ was supplied by Boulder Scientific, USA and $\mathrm{SiMe}_{2}$ (Ind) ${ }_{2} \mathrm{ZrCl}_{2}$ came from Wako Pure Chemical Inc. Both were used as received.

\section{Preparation of the supported catalyst}

Silica Gel was heated at $400{ }^{\circ} \mathrm{C}$ for $4 \mathrm{~h}$., under nitrogen flow.

Both zeolites were used as support material after remaining for eight hours at $120^{\circ} \mathrm{C}$. Afterwards, they have been heated up to $300{ }^{\circ} \mathrm{C}$, under nitrogen flow (heating rate of $2{ }^{\circ} \mathrm{C} / \mathrm{min}$ ) and kept at that temperature for further $2 \mathrm{~h}$.

Silica Gel (1) was pre-treated with MAO (5mmol/g support) solution in toluene; the solution (room temperature) was stirred for $8 \mathrm{~h}$. The mixture was filtered and washed with hot toluene. $\mathrm{NaM}(2)$ and HM(3) were used without chemical pre-treatment.

After that, the metallocene solution was submitted to reaction with the solid part (1), (2) or (3) in the concentration of $0,05 \mathrm{mmol} \mathrm{Zr} / \mathrm{g}$ support. The resulting catalysts were evaluated for propylene polymerization, in toluene, pentane and hexane as diluents.

The $\mathrm{Zr}$ content on the support was determined by ICP Spectroscopy Plasma Emission. The sample was treated with chloridric, nitric, fluoridric and perchloric acids and heated by using a microwave oven. A solution was prepared in a volumetric flask and the contents were determined in a Perkin Elmer 2000, calibrated with standard solutions containing known amounts of the same concentration magnitude of the analyzed solutions. Each sample was analyzed in duplicate with two readings per analysis and the variation coefficient of the results was bellow $5 \%$.

\section{Polymerization}

Propylene polymerization was carried out in a 0.5 -L Büchi glass autoclave filled with $100 \mathrm{ml}$ of toluene, pentane or hexane as diluent; $0.025 \mathrm{~mol}$ of TIBA, a varying amount of MAO $(10 \%$ solution), monomer and $100 \mathrm{mg}$ of catalyst were added in sequence while stirring vigorously at different temperatures. Polymerizations were terminated by adding $\mathrm{HCl}$ in ethanol solution $(5 \% \mathrm{v} / \mathrm{v})$. The obtained polymer was adequately washed with ethanol and dried under vacuum at $60{ }^{\circ} \mathrm{C}$ to constant weight.

\section{Polymer characterization}

The weight-average molecular weight $(\mathrm{Mw})$ and polydispersity $(\mathrm{Mw} / \mathrm{Mn})$ were determined by Gel Permeation Chromatography (GPC) (Waters-150-CV-Plus) equipped with a set of columns styragel HT6, HT3, HT4 from Waters, calibrated with standard polystyrene and using 1,2,4trichlorobenzene as eluent. Polymer thermal characteristics were examined by Differential Scanning Calorimetry (Perkin Elmer DSC7) with a heating rate of $10^{\circ} \mathrm{C} / \mathrm{min}$. The amount of syndiotactic (rrrr \%) and isotactic ( $\mathrm{mmmm} \%)$ pentads were estimated through calibration curves ${ }^{[7]}$ and ${ }^{[8]}$, respectively. The s-PP's used for calibration, as well as the i-PP's, were prepared with the same metallocene complexes used in this work and their $\%$ rrrr and $\%$ mmmm were obtained by ${ }^{13} \mathrm{C}-\mathrm{NMR}$ (Nuclear Magnetic Resonance). ${ }^{13} \mathrm{C}$-NMR spectra were recorded on a Bruker NMR 300 spectrometer operating at $75,4 \mathrm{MHz}$, with the probe at $95{ }^{\circ} \mathrm{C}$. Sample solutions were prepared by dissolving $200 \mathrm{mg}$ of polymer in $3 \mathrm{~mL}$ of trichlorobenzene with $0.5 \mathrm{~mL}$ of Deuterobenzene. The micrographies of the polymers were carried out in an optic microscope (Olympus model SZ 10) connected to a camera.

\section{Statistical Analysis}

Experiments used a two factorial design with uniform differences in the parameters level ${ }^{[9]}$. The reaction parameters were the polymerization temperature $(\mathrm{x} 1)$ and the $[\mathrm{Al}] /[\mathrm{Zr}](\mathrm{x} 2)$.

The experimental design allowed the calculation of empirical equations for catalyst activity (Y1). The correlation $\mathrm{R}$ was also calculated. For this purpose, the software STATISTICA for Windows was used. The experiments consisted of 7 trials including three runs in the design centre. Within the trials, the order of the run was randomised.

\section{Results and Discussion}

\section{Preliminary results}

The results of propylene polymerization using $\phi_{2} \mathrm{C}(\mathrm{Flu})$ (Cp) $\mathrm{ZrCl}_{2}$ in homogeneous and silica or zeolite-supported systems, performed in toluene as reaction solvent are presented in Table 1.

Table 1. Propylene Polymerization with syndiospecific homogeneous and supported systems in toluene $100 \mathrm{ml}$ toluene $([\mathrm{Zr}]=0.005 \mathrm{mmol}(\mathrm{homog}$.); 100 $\pm 10 \mathrm{mg}$ of supported $\phi_{2} \mathrm{C}(\mathrm{Flu})(\mathrm{Cp}) \mathrm{ZrCl}_{2}$ catalyst; $0.1 \mathrm{M}$ of MAO; 2 bar of propylene; $\left.1 \mathrm{~h} ; 60{ }^{\circ} \mathrm{C}\right)$

\begin{tabular}{cccccccc}
\hline Catalyst & $\begin{array}{c}\mathbf{Z r} \\
(\mathbf{m m o l} / \mathbf{g} \text { support })\end{array}$ & $\begin{array}{c}\text { Yield } \\
(\mathbf{g})\end{array}$ & $\mathbf{a}$ & $\mathbf{M w . 1 0 - 5}$ & Mw/Mn & $\begin{array}{c}\text { Tm } \\
\left({ }^{\circ} \mathbf{C}\right)\end{array}$ & $\begin{array}{c}\text { Crystallinity } \\
(\mathbf{\%})\end{array}$ \\
\hline $\begin{array}{c}\text { Homog. } \\
\begin{array}{c}(1) \\
\mathrm{Cat} / \mathrm{SiO}{ }_{2}\end{array}\end{array}$ & - & 30 & 113 & 0.6 & 2.6 & - & 0 \\
$\begin{array}{c}(2) \\
\mathrm{Cat} / \mathrm{NaM}\end{array}$ & 0.034 & 20 & 111 & 1.3 & 2.8 & 106 & 9.8 \\
\hline
\end{tabular}

catalyst activity in a TonPP/mol $\mathrm{Zr}[\mathrm{M}] \mathrm{h}$ 
Table 2. Polypropylene pentad distribution - polymerizations in toluene

\begin{tabular}{|c|c|c|c|c|c|c|c|c|c|c|}
\hline Catalyst & $\begin{array}{c}\delta \\
(\mathbf{p p m})\end{array}$ & $\begin{array}{c}\text { I } \\
(21.8)\end{array}$ & $\underset{(21.5)}{\text { II }}$ & $\underset{(21.3)}{\text { III }}$ & $\underset{(21.0)}{\text { IV }}$ & $\begin{array}{c}\mathrm{V} \\
(20.8)\end{array}$ & $\begin{array}{c}\text { VI } \\
(20.7)\end{array}$ & $\begin{array}{c}\text { VII } \\
(20.3)\end{array}$ & $\begin{array}{l}\text { VIII } \\
(20.2)\end{array}$ & $\underset{(20.0)}{\text { IX }}$ \\
\hline & rmrr/ $\mathbf{m m r r}$ & mmmm & mmmr & rmmr & rrmm & rrmr + mmrm & rmrm & rrrr & rrrm & mrrm \\
\hline Homog. & 3.16 & 0.00 & 0.77 & 2.07 & 4.33 & 13.69 & 3.02 & 54.51 & 19.12 & 2.41 \\
\hline $\begin{array}{c}(1) \\
\mathrm{Cat} / \mathrm{SiO}_{2}\end{array}$ & 2.43 & 0.00 & 0.63 & 1.79 & 3.99 & 9.70 & 3.02 & 65.83 & 15.04 & 0.00 \\
\hline $\begin{array}{c}(2) \\
\mathrm{Cat} / \mathrm{NaM}\end{array}$ & 2.23 & 0.00 & 0.41 & 1.74 & 3.45 & 7.69 & 3.61 & 65.94 & 17.15 & 0.00 \\
\hline
\end{tabular}

The obtained results show that the activity of the silicasupported catalyst system was surprisingly as high as that of the homogeneous precursor, in spite of the bulkiness of the metallocene molecule. On the other hand, the NaM-supported catalyst presented around half of the activity compared to that of the homogeneous system.

The polymers synthesized by both supported systems showed higher Mw comparing to the s-PP obtained with the homogeneous catalyst under similar conditions. The increase in the polymer molecular weight can be explained by the stabilization of the active sites fixed on a support surface. Moreover, an action of inert solid should to be considered, regarding the absorption of the high reaction heat at the active sites, which lowers the chain transfer reactions.

The catalyst system (1) produced polypropylene with narrow molecular weight distribution. Moreover, the polymer obtained by catalyst (2) presented the highest Mw. This behavior is a characteristic of the NaM when used as support for metallocene system ${ }^{[10]}$.

Both supported systems produced polymers with close melting temperature, although the crystallinity degree of the polypropylene obtained by employing the NaM-supported

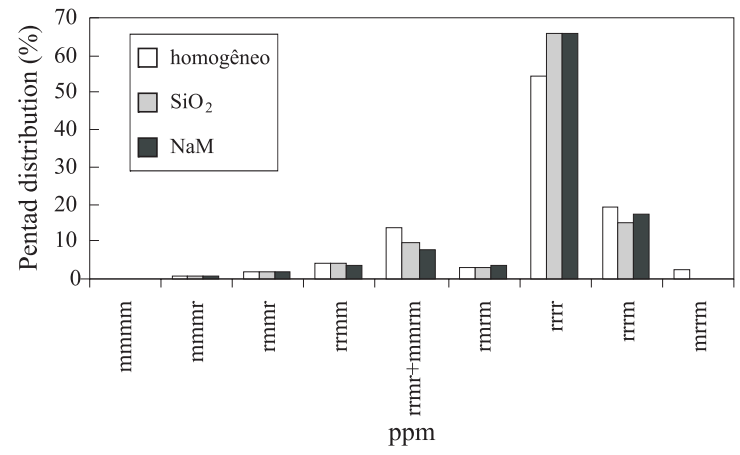

Figure 1. Polypropylene pentad distribution - polymerization in toluene system was slightly higher than that of the $\mathrm{SiO}_{2}$-supported one. On the other hand, the homogeneous precursor produced PP without melting endotherm peak on the DSC curve.

Table 2 and Figure 1 shows the polypropylene pentad distribution obtained using toluene as polymerization solvent.

The syndiotactic PP synthesised by the NaM-supported catalyst showed higher crystalline melting temperature due to the less occurrence of stereoerrors caused by monomer missinsertion. In this case, the contents of $\mathrm{mmmr}, \mathrm{rmmr}$, rrmm and rrmr were lower and the content of rrrr were superior in comparison to the other polymers. The rmrr/mmrr ratio is related to the isomerisation of the active site ${ }^{[11]}$. This ratio decreased in the polymers synthesized with both supported systems in relation to that of the homogeneous one. This fact indicates that the supported systems admit less isomerization of the active site.

The results of propylene polymerization with the syndiospecific catalyst using pentane as reaction solvent are shown in Table 3.

Using the same catalysts and changing the reaction solvent from toluene to pentane, the yield of propylene polymerization with the metallocene systems was reduced. This behavior was due to numerous factors such as lower solubility of both monomer and cocatalyst in pentane. Another reason to be considered is the tighter interaction between the zirconium cation complex and the counterion in nonpolar solvents as pentane. As can be observed in Table 3, both melting temperature and crystallinity degree of the produced polymers were higher in the polymerization in pentane than in toluene.

Multiple melting endoterms were observed in s-PP produced by the catalyst (1) under appropriate conditions. Marigo et al. ${ }^{[12]}$ associated the multiple melting behaviour of $\mathrm{s}-\mathrm{PP}$ to a reorganization phenomenon in the melting region.

Table 3. Propylene Polymerization with syndiospecific supported systems in pentane

\begin{tabular}{ccccccc}
\hline Catalyst & $\begin{array}{c}\text { Yield } \\
\text { (g) }\end{array}$ & $\begin{array}{c}\text { Catalyst Activity } \\
(\text { TonPP/mol Zr[M] h) }\end{array}$ & $\mathbf{M w . 1 0}^{-5}$ & $\mathbf{M w} / \mathbf{M n}$ & $\begin{array}{c}\text { Tm } \\
\left({ }^{\circ} \mathbf{C}\right)\end{array}$ & $\begin{array}{c}\text { Crystallinity } \\
(\%)\end{array}$ \\
\hline $\begin{array}{c}(\mathrm{cat} 1) \\
\mathrm{Cat} / \mathrm{SiO} \mathrm{O}_{2}\end{array}$ & 3.0 & 600 & 0.7 & 2.8 & $90 / 110$ & 9.5 \\
$\begin{array}{c}(\mathrm{cat} 2) \\
\mathrm{Cat} / \mathrm{NaM}\end{array}$ & 8.0 & 1600 & 1.7 & 2.4 & 117 & 14.0 \\
\hline
\end{tabular}

$100 \mathrm{ml}$ pentane; $100 \pm 10 \mathrm{mg}$ of supported $\phi_{2} \mathrm{C}(\mathrm{Flu})(\mathrm{Cp}) \mathrm{ZrCl} 2$ catalyst; $0.1 \mathrm{M}$ of MAO; 2 bar of propylene; $1 \mathrm{~h} ; 60^{\circ} \mathrm{C}$ 
Table 4. Polypropylene pentad distribution-polymerization with $\phi_{2} \mathrm{C}(\mathrm{Flu})(\mathrm{Cp}) \mathrm{ZrCl}_{2}$ in pentane

\begin{tabular}{|c|c|c|c|c|c|c|c|c|c|c|}
\hline \multirow{2}{*}{ Catalyst } & $\begin{array}{c}\mathbf{d} \\
(\mathbf{p p m})\end{array}$ & $\begin{array}{c}\text { I } \\
(21.8)\end{array}$ & $\underset{(21.5)}{\text { II }}$ & $\underset{(21.3)}{\text { III }}$ & $\underset{(21.0)}{\text { IV }}$ & $\begin{array}{c}\mathbf{V} \\
(20.8)\end{array}$ & $\begin{array}{c}\text { VI } \\
(20.7)\end{array}$ & $\begin{array}{c}\text { VII } \\
(\mathbf{2 0 . 3})\end{array}$ & $\begin{array}{l}\text { VIII } \\
(20.2)\end{array}$ & $\begin{array}{c}\text { IX } \\
(20.0)\end{array}$ \\
\hline & rmrr/ mmrr & mmmm & mmmr & rmmr & rrmm & $\mathbf{r r m r}+\mathbf{m m r m}$ & rmrm & rrrr & rrrm & mrrm \\
\hline $\begin{array}{c}(1) \\
\mathrm{Cat} / \mathrm{SiO}_{2}\end{array}$ & 2.64 & 0.00 & 0.29 & 1.35 & 3.28 & 8.67 & 2.14 & 65.67 & 16.71 & 1.85 \\
\hline $\begin{array}{c}(2) \\
\mathrm{Cat} / \mathrm{NaM}\end{array}$ & 2.25 & 0.00 & 0.29 & 1.40 & 2.99 & 6.73 & 1.56 & 71.97 & 12.69 & 1.87 \\
\hline
\end{tabular}

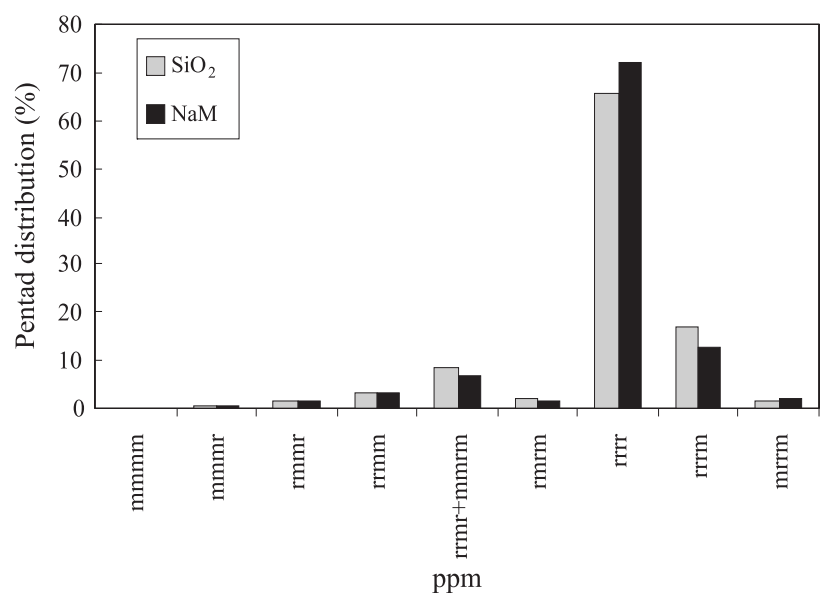

Figure 2. Polypropylene pentad distribution - polymerization in pentane
Table 4 and Figure 2 present the polypropylene NMR pentad signals in the polymerization in pentane.

The polymers stereoregularity levels were greater in the polymerizations in pentane. The rrrr pentad contents of sPP's obtained in pentane, either by $\mathrm{SiO}_{2}$ or in NaM supported catalyst, were higher in relation to those obtained at the polymerization in toluene.

\section{Homogeneous catalyst systems $\phi_{2} \mathrm{C}(\mathrm{Flu})(\mathrm{Cp}) \mathrm{ZrCl}_{2}$ and $\mathrm{SiMe}_{2}(\mathrm{Ind})_{2} \mathrm{ZrCl}_{2}$}

The homogeneous polymerizations were performed using syndiospecific and isospecific catalyst systems at different polymerization temperatures, with constant $\mathrm{Al} / \mathrm{Zr}$ molar ratio and fixed propylene pressure.

Tables 5 and 6 show the results of weight-average molecular weight, polydispersity, Tm and stereoregularity for

Table 5. Polymerization of propylene with homogeneous $\phi_{2} \mathrm{C}(\mathrm{Flu})(\mathrm{Cp}) \mathrm{ZrCl}_{2} / \mathrm{MAO}$

\begin{tabular}{|c|c|c|c|c|c|c|c|c|}
\hline Exp. & $\begin{array}{c}\mathbf{T} \\
\left({ }^{\mathbf{C}} \mathbf{C}\right)\end{array}$ & $\begin{array}{c}\text { Yield } \\
\text { (g) }\end{array}$ & {$[\mathbf{M}]$} & $\begin{array}{c}\text { a } \\
\text { (Ton PP/mol } \\
\operatorname{Zr}[\mathrm{M}] \mathbf{h})\end{array}$ & $\begin{array}{l}\text { Tm } \\
\left({ }^{\circ} \mathbf{C}\right)\end{array}$ & $M w^{*} 10^{-5}$ & $\begin{array}{l}\Delta \mathbf{H} \\
(\mathbf{J} / \mathbf{g})\end{array}$ & Mw/Mn \\
\hline $1^{\mathrm{a}}$ & 0 & 5.0 & 6.8 & 1.5 & 141.3 & 5.9 & 28.9 & 2.1 \\
\hline $2^{\mathrm{a}}$ & 20 & 68.0 & 3.1 & 44.0 & - & 1.6 & 0 & 3.1 \\
\hline $3^{\mathrm{a}}$ & 40 & 65.1 & 1.8 & 72.9 & - & 1.4 & 0 & 2.7 \\
\hline $4^{a}$ & 60 & 63.7 & 1.4 & 88.2 & - & 0.8 & 0 & 2.9 \\
\hline $5^{b}$ & 60 & 29.7 & 1.3 & 45.7 & - & 0.3 & 0 & 2.0 \\
\hline $6^{c}$ & 60 & 31.0 & 1.3 & 47.7 & - & 0.3 & 0 & 2.6 \\
\hline
\end{tabular}

$100 \mathrm{ml}$ toluene; $[\mathrm{Zr}]=50 \mu \mathrm{M} ; \mathrm{MAO}=0.1 \mathrm{M} ; 1 \mathrm{~h} ; \mathrm{P}_{\text {propylene }}=4 \mathrm{bar}$;

a -polymerization in toluene

c-polymerization in hexane with $0.025 \mathrm{M}$ TIBA

Table 6. Polymerization of propylene with $\mathrm{SiMe}_{2}(\mathrm{Ind})_{2} \mathrm{ZrCl}_{2}$ homogeneous catalyst system

\begin{tabular}{|c|c|c|c|c|c|c|c|c|c|}
\hline Exp. & $\begin{array}{c}\mathbf{T} \\
\left({ }^{\circ} \mathbf{C}\right)\end{array}$ & $\begin{array}{c}\text { Yield } \\
(\mathrm{g})\end{array}$ & {$[\mathbf{M}]$} & $\begin{array}{c}\text { a } \\
\text { (Ton PP/mol Zr[M]h) }\end{array}$ & $\begin{array}{l}\text { Tm } \\
\left({ }^{\circ} \mathbf{C}\right)\end{array}$ & $\underset{(\mathrm{J} / \mathrm{g})}{\Delta \mathbf{H}}$ & $M w^{*} 10^{-5}$ & Mw/Mn & $\begin{array}{c}\operatorname{mmmm}^{\mathrm{d}} \\
(\%)\end{array}$ \\
\hline $7^{\mathrm{a}}$ & 0 & 5.8 & 6.8 & 1.7 & 152.5 & 69.5 & 2.3 & 2.2 & 88.9 \\
\hline $8^{\mathrm{a}}$ & 20 & 64.0 & 3.1 & 41.5 & $130.0 / 140.5$ & 16.4 & 0.2 & 2.3 & 76.3 \\
\hline $9^{a}$ & 40 & 92.1 & 1.8 & 103.2 & $114.2 / 127.4$ & 7.7 & 0.3 & 3.0 & 74.8 \\
\hline $10^{\mathrm{a}}$ & 60 & 83.7 & 1.4 & 115.8 & $115.3 / 125.8$ & 31.0 & 0.3 & 2.7 & 68.0 \\
\hline $11^{\mathrm{a}}$ & 80 & 66.7 & 0.8 & 173.0 & $87.0 / 102.6$ & 31.1 & 0.2 & 2.5 & 60.9 \\
\hline $12^{\mathrm{b}}$ & 60 & 29.8 & 1.3 & 46.6 & $131.0 / 137.9$ & 57.3 & 0.1 & 1.8 & 74.6 \\
\hline $13^{c}$ & 60 & 57.5 & 1.3 & 89.8 & $127.1 / 134.3$ & 54.5 & 0.1 & 1.6 & 76.8 \\
\hline
\end{tabular}

$100 \mathrm{ml}$ toluene; $[\mathrm{Zr}]=50 \mu \mathrm{M} ; \mathrm{MAO}=0.1 \mathrm{M} ; 1 \mathrm{~h} ; \mathrm{P}_{\text {propylene }}=4 \mathrm{bar}$;

a -polymerization in toluene

${ }^{\mathrm{b}}$-polymerization in hexane

c -polymerization in hexane with $0.025 \mathrm{M}$ TIBA

$\mathrm{d}$-obtained through calibration curve ${ }^{[8]}$ 


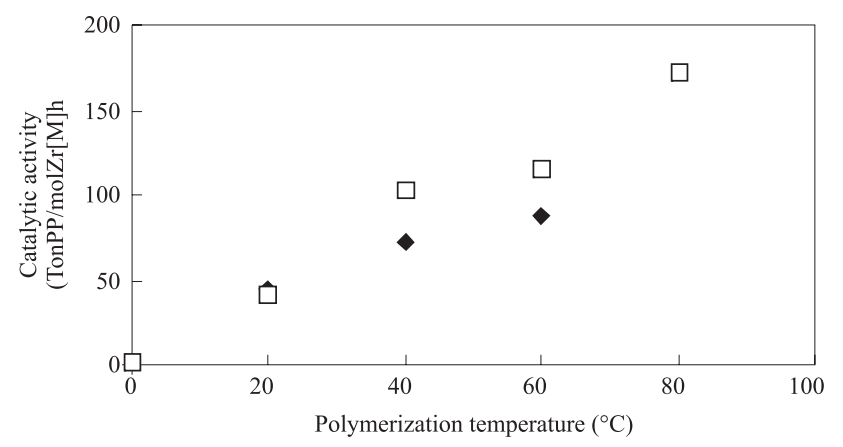

Figure 3. Polymerization temperature $\left({ }^{\circ} \mathrm{C}\right) \mathrm{x}$ Catalyst activity (TonPP/ molZr[M]h) of the homogeneous catalyst systems $\phi_{2} \mathrm{C}(\mathrm{Flu})(\mathrm{Cp}) \mathrm{ZrCl}_{2}(\bullet$ e $\mathrm{SiMe}_{2}(\mathrm{Ind})_{2} \mathrm{ZrCl}_{2}(\square)$

the polymers produced through both homogeneous systems, as well as the catalyst activities.

An increase of the catalyst activity at higher polymerization temperature can be observed, whereas the polymer molecular weight have sharply decreased when employing both homogeneous systems. This behavior was due to the occurrence of more beta-hydrogen chain transfer reactions at higher polymerization temperatures.

Syndiotatic PP obtained through experiments 2 and 4 showed higher polydispersion due to the chain transfer reactions and to a possible initial lack of polymerization temperature control at high activities. Figure 3 shows the influence of polymerization temperature on the catalyst activity.

The polymers did not show melting behaviour when produced at high polymerization temperatures, owing to the stereoerrors that occurred in the polymer chain at high polymerization rate, consequently decreasing the catalyst stereoselectivity.

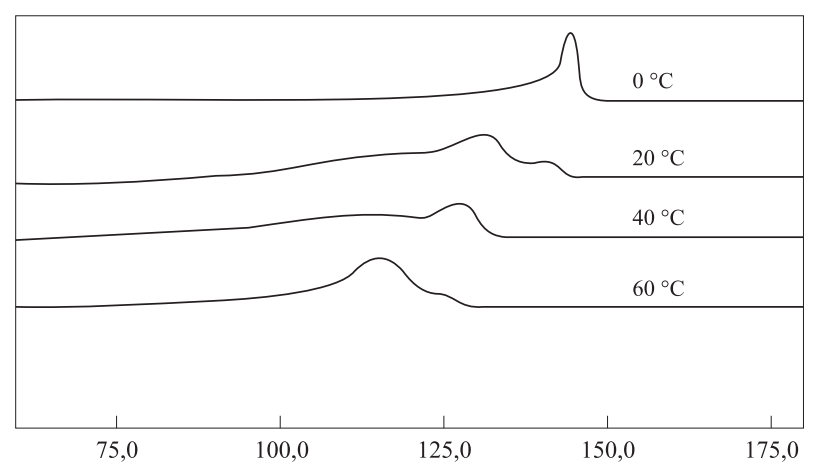

Figure 4. Isotactic polypropylene DSC curves (experiments 7, 8, 9 and 10)

Multiple melting endotherms in the obtained isotactic polypropylenes (iPP's) can be observed under appropriate conditions, which is associated to a reorganization phenomenon in the melting region or to the polymorphism of iPP ${ }^{[13]}$. However, an initial lack of temperature control has possibly occurred at high polymerization activities, due to the reaction exotermicity. In this case, the polypropylene chains obtained in higher temperatures have more stereoerrors and consequently, lower Tm compared to the polymers obtained in lower temperatures. This might indicate that the obtained PP contains a mixture of chains with diverse microstructures. Nevertheless, in the experiment 12 , whose catalyst activity was relatively low and whose polymer presented narrow molecular weight distribution, two melting endotherms were observed in the calorimetric analysis. Figure 4 shows curves of the second run of DSC analysis for the obtained i-PP's.

Low activities were observed for both systems using hexane as diluent in relation to the reactions carried out in

Table 7. Experimental results of propylene polymerization with $\phi_{2} \mathrm{C}(\mathrm{Flu})(\mathrm{Cp}) \mathrm{ZrCl}_{2}$ supported on $\mathrm{HM}$

\begin{tabular}{cccccccccc}
\hline Exp. & $\begin{array}{c}\mathbf{T p} \\
\left({ }^{\circ} \mathbf{C}\right)\end{array}$ & {$[\mathbf{A l}] /[\mathbf{Z r}]$} & $\mathbf{P r}^{\mathbf{b}}$ & $\begin{array}{c}\mathbf{a} \\
(\mathbf{T o n P P / m o l Z r}[\mathbf{M}] \mathbf{h})\end{array}$ & $\begin{array}{c}\mathbf{T m} \\
\left({ }^{\circ} \mathbf{C}\right)\end{array}$ & $\begin{array}{c}\Delta \mathbf{H} \\
(\mathbf{J} / \mathbf{g})\end{array}$ & $\mathbf{M w 1 0}^{-5}$ & $\mathbf{M w / M n}$ & $\begin{array}{c}\mathbf{r r r r}^{\mathbf{c}} \\
(\%)\end{array}$ \\
\hline $6^{\mathrm{a}}$ & 60 & 1000 & - & 47.7 & - & 0 & 0.3 & 2.6 & - \\
14 & 60 & 1000 & 163.0 & 17.6 & 110.0 & 10.3 & 2.2 & 2.2 & 65 \\
15 & 60 & 100 & 0.0 & 0.0 & - & - & - & - & - \\
16 & 0 & 1000 & 5.8 & 0.1 & 146.2 & 21.0 & 5.3 & 2.2 & 100 \\
17 & 0 & 100 & 0.0 & 0.0 & - & - & - & - & - \\
18 & 30 & 550 & 74.5 & 3.7 & $132.0 / 139.0$ & 23.4 & 5.3 & 2.0 & 99 \\
19 & 30 & 550 & 78.5 & 4.0 & n.d. & n.d. & 4.7 & 2.4 & n.d. \\
20 & 30 & 550 & 108.0 & 5.3 & n.d. & n.d. & 5.1 & 2.1 & n.d. \\
21 & 30 & 450 & 48.9 & 2.4 & $136.5 / 142.3$ & 24.5 & 4.7 & 2.2 & 96 \\
22 & 80 & 1000 & 203.0 & 38.4 & - & 0 & 0.6 & 2.3 & - \\
\hline
\end{tabular}

$100 \mathrm{ml}$ hexane; $100 \pm 10 \mathrm{mg}$ of supported catalyst; $\mathrm{Zr}]=50 \mu \mathrm{M} ; 0.025 \mathrm{M}$ TIBA; 4 bar of propylene; $1 \mathrm{~h}$

${ }^{a}$ Homogeneous polymerization $([\mathrm{Zr}]=0.005 \mathrm{mmol})$

b Productivity $\mathrm{gPP} / \mathrm{g}$ catalyst

${ }^{c}$ Obtained through of calibration curve ${ }^{[7]}$ 
toluene. On the other hand, the isospecific catalyst responded strongly to the addition of TIBA in the reaction medium, increasing its activity, but slightly decreasing the Tm's of the obtained polymers.

On the other hand, the i-PP's synthesized in hexane (experiments 12 and 13) showed higher melting temperatures compared to the polymers obtained in toluene (experiment 10) under the same polymerization conditions, and therefore, higher isotacticity. This fact was attributed to the lower amounts of stereoerrors when the polymerization medium is nonpolar.

\section{Supported Catalyst systems}

\section{Catalysts systems $\phi_{2} \mathrm{C}(\mathrm{Flu})(\mathrm{Cp}) \mathrm{ZrCl}_{2}$ supported on $\mathrm{HM}$}

The polymerization results and the obtained s-PP characteristics are presented in Table 7. For comparison, the homogeneous catalyst precursor was also evaluated in propylene polymerization.

The results obtained through homogeneous (exp. 6) and the heterogeneous (exp. 14) systems showed some differences. The polymer properties were improved by the catalyst heterogeneization. Polymers with superior Tm and Mw's were obtained. Regarding the catalyst performance, the homogeneous system showed higher activities than the heterogeneous one. The decrease of the activity may be due to the catalyst deactivation during the impregnation process. The fixed $\mathrm{Zr}$ content on the support surface does not represent the $\mathrm{Zr}$ amount that will be active or available for the polymerization.

In both cases, a decrease in the Mw was observed when the polymerization temperature was increased. However, polymers with superior Mw were obtained through supported systems, in comparison with those obtained through the homogeneous system.

All reactions with the supported catalysts produced polymers with narrower molecular weight distribution $(\mathrm{Mw} / \mathrm{Mn} \cong 2)$,

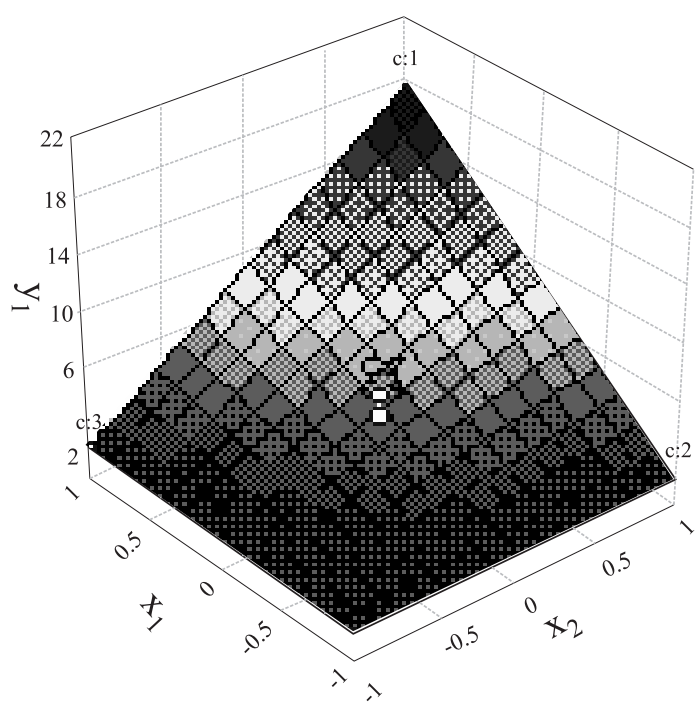

Figure 5. Influence of polymerization $\mathrm{T}\left(\mathrm{x}_{1}\right)$ and $[\mathrm{Al}] /[\mathrm{Zr}]\left(\mathrm{x}_{2}\right)$ on the supported catalyst activity $\left(\mathrm{Y}_{1}\right)$. Normalized variables in the range of $0-60{ }^{\circ} \mathrm{C}$ and $[\mathrm{Al}] /[\mathrm{Zr}]=100-1000$ indicating the presence of only one type of active species. This means that the metallocene leaching out of the support surface during the polymerization was not extensive, since the presence of homogeneous active sites together with the supported ones would have lead to an increase in the polymer polydispersity. Moreover, in the case of the syndiospecific metallocene, the supported system produced polymers with some crystallinity, which was not observed in the s-PP obtained from the homogeneous precursor. This fact denotes an increase in the stereospecificity for the heterogeneous catalyst, probably due to the more sterical hindrance around the metallocene complex when fixed on the support surface, which leads to less stereoerrors monomer insertions.

The influence of polymerization temperature $\left(0\right.$ to $\left.60^{\circ} \mathrm{C}\right)$ and $[\mathrm{Al}] /[\mathrm{Zr}]$ in the reaction medium (100 to1000) on the catalyst activity was mathematically treated using the program Statistica for Windows ${ }^{\circledR}$, through the normalized variables $(-1$ to +1$)$.

The performance of the supported metallocene system regarding the studied variables can be expressed by the Equation 1 below and is represented in Figure 5.

$(\mathrm{Y} 1)=4.37 \times 1+4.43 \times 2+3.37 \times 1 \times 2+4.37(\mathrm{R}=0.9967)$

Where:

$\mathrm{x} 1=$ normalized reaction temperature

$\mathrm{x} 2=$ normalized $\mathrm{Al} / \mathrm{Zr}$ ratio

$\mathrm{Y} 1=$ catalyst activity

$\mathrm{R}=$ correlation coefficient

According to these results, polymerization at MAO concentration corresponding to $[\mathrm{Al}] /[\mathrm{Zr}]=100 \mathrm{did}$ not present catalyst activity between 0 and $60^{\circ} \mathrm{C}$. At $[\mathrm{Al}] /[\mathrm{Zr}]=1000$ and $0{ }^{\circ} \mathrm{C}$, the activity was very low. On the other hand, a strong increase in the catalyst activity was observed with the increase of both polymerization temperature and $\mathrm{Al} / \mathrm{Zr}$ molar ratio in the studied range.

The experiment 9 was performed in order to evaluate the validity of the calculated model. By employing the normalized values of the variables at $30{ }^{\circ} \mathrm{C}\left(\mathrm{x}_{1}=0\right)$ and $\mathrm{Al} / \mathrm{Zr}=450$ $\left(\mathrm{x}_{2}=-0.22\right)$, we have calculated the activity according to the proposed model, resulting in $\mathrm{Y}=3.4$. The experimental result (exp. 9) resulted in $\mathrm{Y}=2.4$, denoting relative error of around $30 \%$. Another experiment was carried out at $80^{\circ} \mathrm{C}$ indicating a sharp increase of the catalyst activity at this condition.

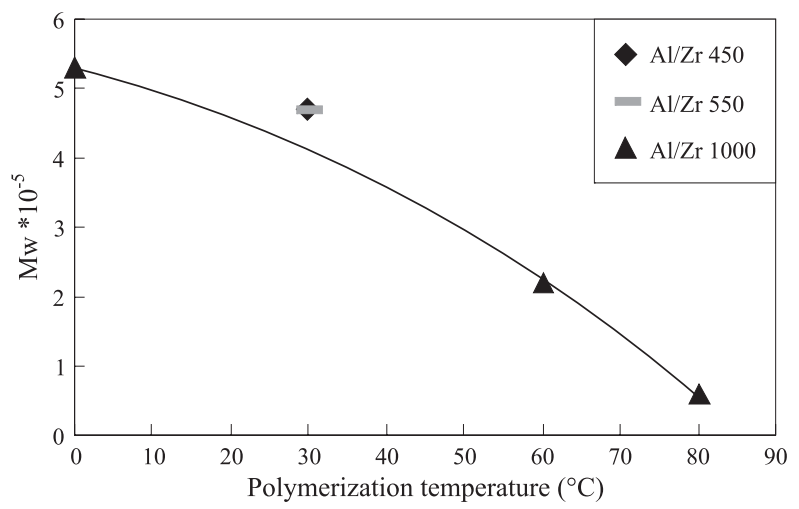

Figure 6. Mw x Polymerization temperature 


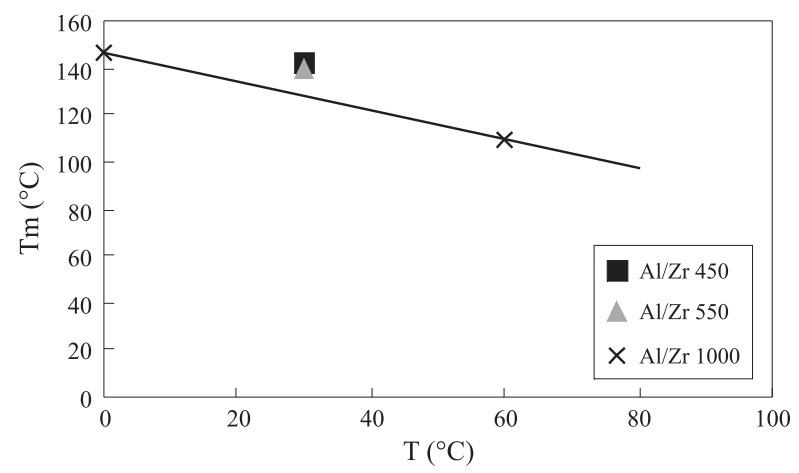

Figure 7. Tm x Polymerization Temperature

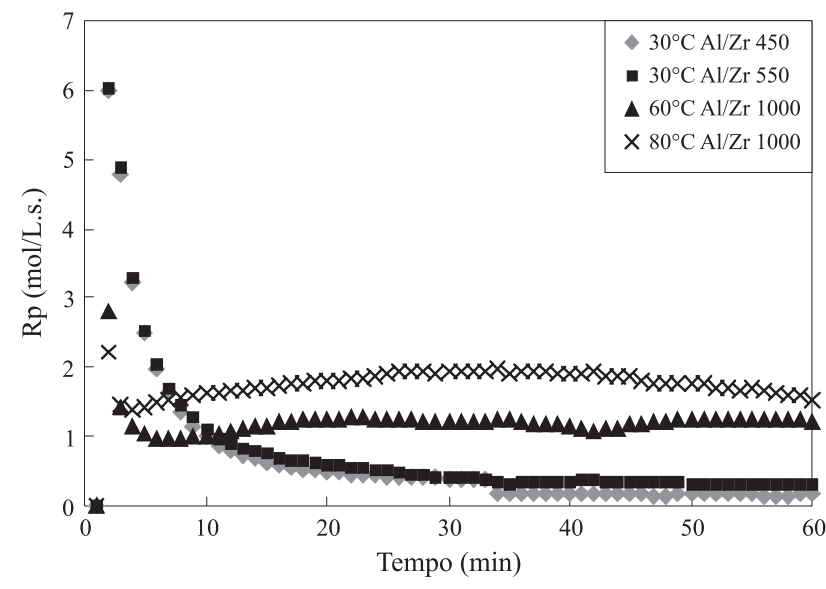

Figure 8. Rate profiles of propylene polymerization with $\phi_{2} \mathrm{C}(\mathrm{Flu})$ (Cp) $\mathrm{ZrCl}_{2} / \mathrm{HM}$
However, the obtained polypropylene showed no melting temperature, and therefore, very low polymer stereoregularity.

The polymers obtained through the HM-supported system showed Mw between 500,000 at $30^{\circ} \mathrm{C}$ and 200,000 at $60^{\circ} \mathrm{C}$, using $\mathrm{Al} / \mathrm{Zr} 1000$.

Figure 6 shows the Mw of s-PP's obtained at different polymerization temperatures. As can be seen, the molecular weight decreased in the studied range of temperature, and apparently any sharp effect of the $[\mathrm{Al}] /[\mathrm{Zr}]$ was detected. The experiments relative to $[\mathrm{Al}] /[\mathrm{Zr}]=450$ and 550 have fit the tendency curve of the other experiments at $[\mathrm{Al}] /[\mathrm{Zr}]=1000$.

It is also important to mention that the molecular weight distribution (MWD) was narrow for all experiments employing the HM-supported catalyst. The changes of temperature and $\mathrm{Al} / \mathrm{Zr}$ in the studied range have not affected polymer molecular weight distribution. On the other hand, their melting temperatures have decreased when the polymerization temperature has increased. Figure 7 shows that the $\mathrm{Al} / \mathrm{Zr}$ molar ratio apparently did not have a strong influence on the polymer characteristics.

Figure 8 shows the rate profiles of propylene polymerization at different experimental conditions.

The rate profiles at 60 and $80^{\circ} \mathrm{C}$ show an increasing polymerization rate up to around 30 minutes, and continues approximately constant after that point until the end of reaction.

\section{Catalysts systems $\mathrm{SiMe}_{2}(\mathrm{Ind})_{2} \mathrm{ZrCl}_{2}$ supported on HM}

The polymerization results and the obtained i-PP characteristics are presented in Table 8. For comparison, the

Table 8. Experimental results of propylene polymerization with $\mathrm{SiMe}_{2}(\mathrm{Ind})_{2} \mathrm{ZrCl}_{2} / \mathrm{HM}$

\begin{tabular}{|c|c|c|c|c|c|c|c|c|c|}
\hline Exp. & $\begin{array}{c}\mathbf{T} \\
\left({ }^{\circ} \mathbf{C}\right)\end{array}$ & {$[\mathrm{Al}] /[\mathbf{Z r}]$} & $\operatorname{Pr}^{b}$ & $\frac{\mathrm{a}}{(\mathrm{TonPP} / \mathrm{molZr}[\mathrm{M}] \mathrm{h})}$ & $\begin{array}{l}\text { Tm } \\
\left({ }^{\circ} \mathbf{C}\right)\end{array}$ & $\underset{(\mathrm{J} / \mathrm{g})}{\Delta \mathbf{H}}$ & Mw.10-5 & Mw/Mn & $\underset{(\%)}{\operatorname{mmmm}^{\mathrm{c}}}$ \\
\hline $13^{\mathrm{a}}$ & 60 & 1000 & - & 89.8 & $127.1 / 134.3$ & 54.5 & 0.1 & 1.6 & 77 \\
\hline 23 & 60 & 1000 & 28.0 & 3.0 & 135.8 & 65.8 & 0.4 & 2.2 & 60 \\
\hline 24 & 60 & 300 & 13.8 & 1.5 & 134.6 & 59.2 & 0.5 & 2.2 & 79 \\
\hline 25 & 0 & 1000 & 0.0 & - & - & - & - & - & - \\
\hline 26 & 0 & 300 & 0.0 & - & - & - & - & - & - \\
\hline 27 & 30 & 650 & 5.0 & 0.25 & 145.4 & 48.5 & 1.2 & 2.0 & 85 \\
\hline 28 & 30 & 650 & 5.0 & 0.25 & $138.5 / 147.8$ & 61.0 & 1.2 & 2.0 & 86 \\
\hline 29 & 30 & 650 & 4.0 & 0.20 & 142.4 & 46.7 & 1.2 & 2.0 & 83 \\
\hline 30 & 60 & 650 & 20.0 & 2.2 & 134.8 & 59.2 & 0.2 & 1.9 & 79 \\
\hline 31 & 80 & 1000 & 17.0 & 3.2 & 123.6 & 51.3 & 0.1 & 2.0 & 73 \\
\hline
\end{tabular}

Polymerization conditions: $100 \mathrm{ml}$ hexane; $100 \pm 10 \mathrm{mg}$ of supported catalyst; $[\mathrm{Zr}]=50 \mu \mathrm{M} ; 0.025 \mathrm{M}$ TIBA; 4 bar of propylene; $1 \mathrm{~h}$

${ }^{\text {a }}$ Homogeneous polymerization

${ }^{\mathrm{b}}$ Determined through calibration curve ${ }^{[8]}$

${ }^{c}$ Productivity gPP/g catalyst 


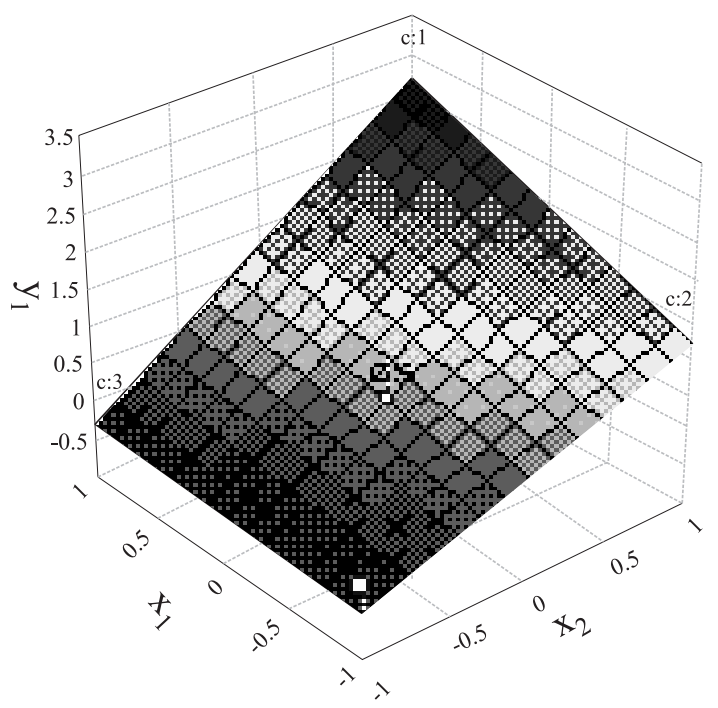

Figure 9. Influence of polymerization temperature $\left(\mathrm{x}_{1}\right)$ and $[\mathrm{Al}] /[\mathrm{Zr}]\left(\mathrm{x}_{2}\right)$ on the catalyst activity $\left(\mathrm{Y}_{1}\right)$. Normalized variables in the range of $0-60{ }^{\circ} \mathrm{C}$ and $\mathrm{Al} / \mathrm{Zr}=300-1000$

homogeneous catalyst precursor was also evaluated in propylene polymerization.

The supported $\mathrm{SiMe}_{2}$ (Ind) $\mathrm{ZrCl}_{2} / \mathrm{HM}$ showed lower activity, concerning the precursor homogeneous system, under the same reaction conditions. Both the iso and syndiospecific systems were prepared at the same method, however, the catalyst $\mathrm{SiMe}_{2}(\mathrm{Ind})_{2} \mathrm{ZrCl}_{2} / \mathrm{HM}$ showed stronger deactivation compared to the $\phi_{2} \mathrm{C}(\mathrm{Flu})(\mathrm{Cp}) \mathrm{ZrCl}_{2} / \mathrm{HM}$. This observation indicates that the preparation method for producing a highly active supported metallocene catalyst depend on the type of complex to be employed.

The polymers obtained from the $\mathrm{SiMe}_{2}(\mathrm{Ind})_{2} \mathrm{ZrCl}_{2}$ supported system showed similar properties of that synthesized with the homogeneous catalyst. Melting temperatures are in the same order of magnitude, while Mw increased slightly from 10,000 to 40,000 .

The activity results were mathematically treated (equation 2) using the program Statistica for windows ${ }^{\mathrm{R}}$ (Figure 9), through the normalized variables $\mathrm{T}\left(0-60^{\circ} \mathrm{C}\right)$ and $[\mathrm{Al}] /[\mathrm{Zr}](300-1000)$.

$\left(\mathrm{Y}_{1}\right)=1.13 \mathrm{x}_{1}+0.38 \mathrm{x}_{2}+0.38 \mathrm{x}_{1} \mathrm{x}_{2}+0.75(\mathrm{R}=0.9052)$

Where:

$\mathrm{x} 1=$ normalized reaction temperature $(-1$ to +1$)$

$\mathrm{x} 2=$ normalized $\mathrm{Al} / \mathrm{Zr}$ ratio $(-1$ to +1$)$

$\mathrm{Y} 1=$ catalyst activity

$\mathrm{R}=$ correlation coefficient

According to these results, polymerization at MAO concentration corresponding to $[\mathrm{Al}] /[\mathrm{Zr}]=300 \mathrm{did}$ not present productivity at $0{ }^{\circ} \mathrm{C}$. In contrast, the $[\mathrm{Al}] /[\mathrm{Zr}]$ has low influence on catalyst activity.

The experiment 30 was performed in order to evaluate the validity of the calculated model. By employing the normalized values of the variables, at $60{ }^{\circ} \mathrm{C}\left(\mathrm{x}_{1}=+1\right)$ and $[\mathrm{Al}] /[\mathrm{Zr}]=$ $650\left(\mathrm{x}_{2}=0\right)$, we have calculated the activity according to the proposed model, resulting in $\mathrm{Y}=1.9$. The experimental result was $\mathrm{Y}=2.2$, meaning a relative error of around $15 \%$.

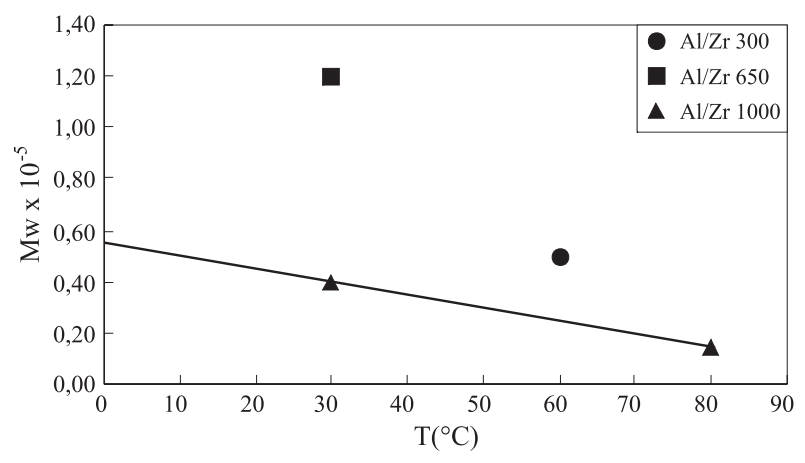

Figure 10. Mw x Polymerization Temperature - $\mathrm{SiMe}_{2}(\mathrm{Ind})_{2} \mathrm{ZrCl}_{2} / \mathrm{HM}$

At higher temperature $\left(80^{\circ} \mathrm{C}\right)$, the obtained iPP showed melting temperature of around $124{ }^{\circ} \mathrm{C}$. The polymers obtained through the heterogeneous catalyst system showed Mw about 120,000 at $30^{\circ} \mathrm{C}$ and 18,000 at $60{ }^{\circ} \mathrm{C}$. At $80^{\circ} \mathrm{C}$ and $[\mathrm{Al}] /[\mathrm{Zr}]=1000$, the Mw was very low.

Figure 10 shows the Mw of iPP obtained at different polymerization temperatures. As can be seen, a detachment of the curve have occurred in relation to the points referred to $[\mathrm{Al}] /[\mathrm{Zr}]=300$ and 650 , showing that $\mathrm{Mw}$ undergo a strong influence of $\mathrm{Al} / \mathrm{Zr}$ ratio, being that higher at lower $\mathrm{Al} / \mathrm{Zr}$ ratio.

Most of the produced iPP showed Tm superior to $130^{\circ} \mathrm{C}$, (Table 8 ) which is due to the high isotactic pentad contents presented in the polymers. Figure 11 shows Tm of the obtained polymers in function of polymerization temperature and $[\mathrm{Al}] /[\mathrm{Zr}]$. In this case, the experiments relative to $[\mathrm{Al}] /[\mathrm{Zr}]=300$

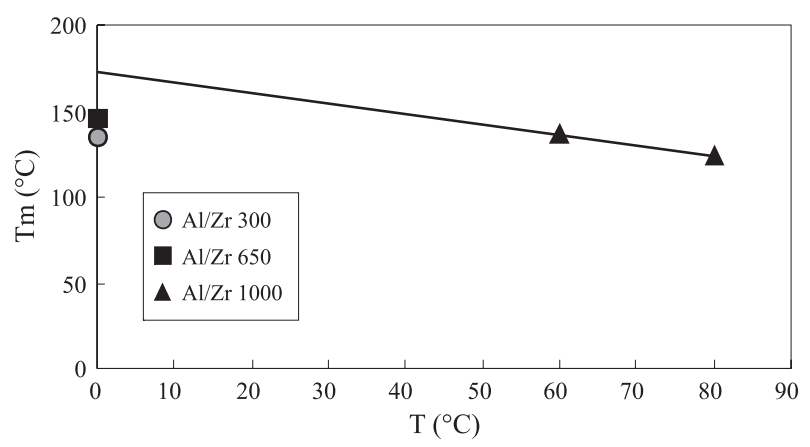

Figure 11. Tm x Polymerization Temperature $-\mathrm{SiMe}_{2}(\mathrm{Ind})_{2} \mathrm{ZrCl}_{2} / \mathrm{HM}$

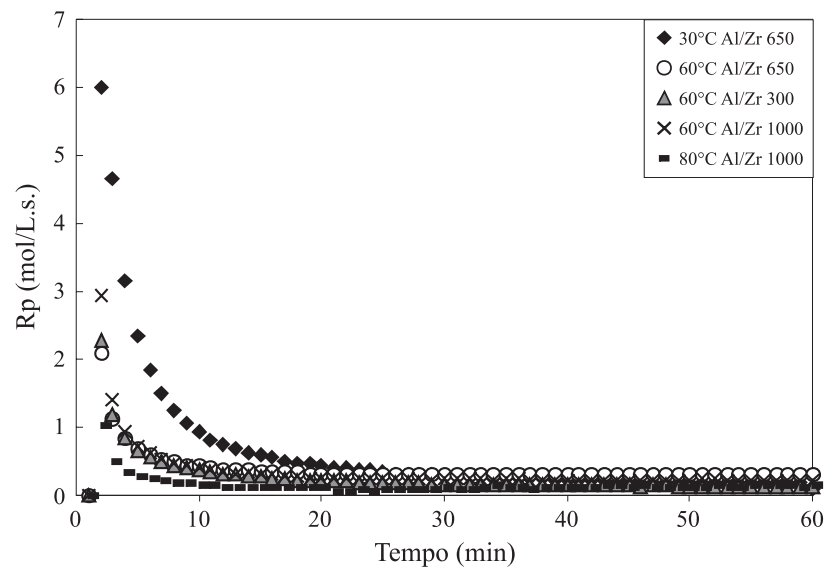

Figure 12. Rate profiles of propylene polymerization $\mathrm{SiMe}_{2}(\mathrm{Ind})_{2} \mathrm{ZrCl}_{2} / \mathrm{HM}$ 


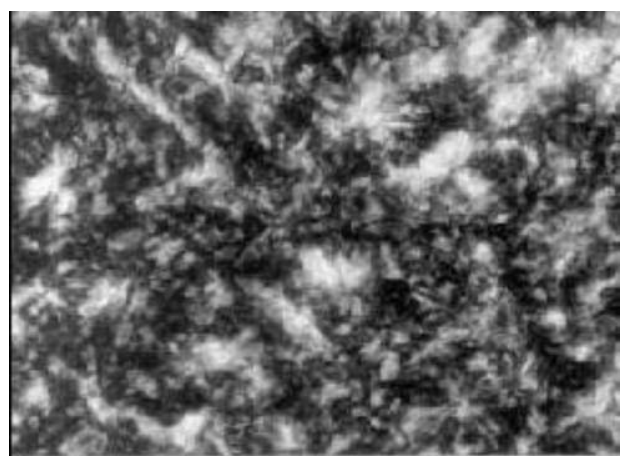

(a)

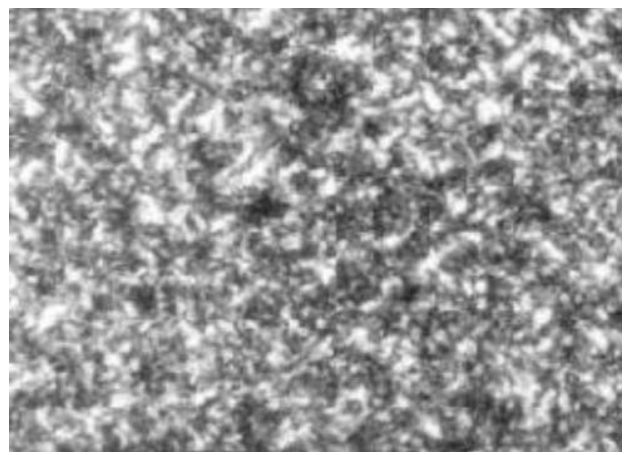

(b)

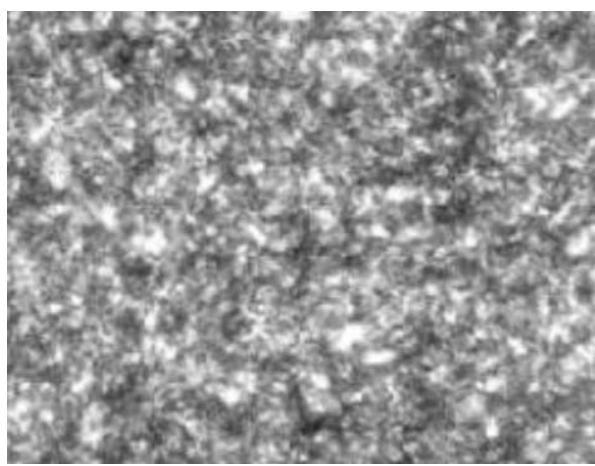

(c)

Figure 13. Micrographies of the polypropylene obtained with the different catalyst systems. (a) PP obtained through homogeneous $\mathrm{SiMe}_{2}(\mathrm{Ind}){ }_{2} \mathrm{ZrCl}_{2}$ (exp. 10); (b) PP obtained from the supported $\mathrm{SiMe}_{2}$ (Ind) $\mathrm{ZrCl}_{2} / \mathrm{HM}$ (exp. 23) and (c) $\mathrm{PP}$ obtained from the supported $\phi_{2} \mathrm{C}(\mathrm{Flu})(\mathrm{Cp}) \mathrm{ZrCl}_{2} / \mathrm{HM}$ (exp. 12)

and 650, have fit the tendency curve, showing that no sharp effect of the variation of $[\mathrm{Al}] /[\mathrm{Zr}]$ was detected the on polymer Tm.

Figure 12 shows the rate profiles of propylene polymerization at different experimental conditions.

The rate profiles for propylene polymerization with this supported system, presented very high rates at the beginning of the reactions, falling in the first minutes until an almost stationary state.

\section{Optic Microscopy}

In this work, the polymers were heated to the melting temperature and afterwards, they were slowly cooled up to room temperature and their micrographies of optical microscopy were recorded. Figure 13 shows the micrographies of the polypropylene obtained with the different catalyst systems.

The isotactic polypropylene obtained from the homogeneous system $\mathrm{SiMe}_{2}$ (Ind) $\mathrm{ZrCl}_{2}$ (Figure 13a) is formed of small and indefinite crystals with amorphous regions. The presented morphology is due to the presence of several stereoerror, characteristic of polypropylene produced by metallocene catalysts ${ }^{[14]}$. On the other hand, the polymer obtained from the supported $\mathrm{SiMe}_{2}$ (Ind) $\mathrm{ZrCl}_{2} / \mathrm{HM}$ (Figure $13 \mathrm{~b})$ showed smaller amorphous region, and therefore greater crystalline regions, compared to the iPP obtained with its precursor.

Figure $12 \mathrm{c}$ shows the micrographies of optical microscopy of s-PP obtained with the supported $\phi_{2} \mathrm{C}(\mathrm{Flu})(\mathrm{Cp}) \mathrm{ZrCl}_{2} / \mathrm{HM}$. It was not possible to observe crystals in the s-PP obtained through the homogeneous precursor, since it was totally amorphous. However, the syndiospecific catalyst when supported on HM, produced polymers with some crystallinity, in spite of the fact that these crystals were small and imperfect.

\section{Conclusions}

The polymer synthesized from the zeolite NaM supported catalyst showed higher $\mathrm{M}_{\mathrm{w}}$ when compared to the $\mathrm{SiO}_{2} / \mathrm{MAO}$ supported system. The sodic mordenite was the support that less influenced the syndiospecifity of the homogeneous precursor. Moreover, the polymerization temperature had a strong influence either on the catalyst activity, and on polymer properties obtained from both homogeneous $\phi_{2} \mathrm{C}(\mathrm{Flu})(\mathrm{Cp}) \mathrm{ZrCl}_{2}$ and $\mathrm{SiMe}_{2}$ (Ind) ${ }_{2} \mathrm{ZrCl}_{2}$ systems. However, Tm and $\mathrm{Mw}$ decreased with the increase of polymerization temperature.

In the supported $\phi_{2} \mathrm{C}(\mathrm{Flu})(\mathrm{Cp}) \mathrm{ZrCl}_{2} / \mathrm{HM}$, a small decrease of the catalyst activity was observed in comparison to the results of the catalyst precursor, whereas the loss of activity with the supported $\mathrm{SiMe}_{2}$ (Ind) ${ }_{2} \mathrm{ZrCl}_{2} / \mathrm{HM}$ was very sharp.

The polymers obtained from the supported systems showed improved properties in comparison to the obtained from the homogeneous systems. Consequently, these supported systems produced polypropylenes with higher Tm and $\mathrm{Mw}$ and lower polydispersity. The catalyst $\phi_{2} \mathrm{C}(\mathrm{Flu})(\mathrm{Cp}) \mathrm{ZrCl}_{2} / \mathrm{HM}$ showed high catalyst activity and their polymers have improved properties in relation to those obtained in the $\mathrm{SiMe}_{2}(\mathrm{Ind})_{2} \mathrm{ZrCl}_{2} / \mathrm{HM}$, prepared in the same impregnation process.

\section{Acknowledgments}

The authors are grateful to Fundação Universitária José Bonifácio-FUJB, Fundação Carlos Chagas Filho de Amparo a Pesquisa do Estado do Rio de Janeiro - FAPERJ, Conselho Nacional de Desenvolvimento Científico e TecnológicoCNPq, Polibrasil, and Crompton.

\section{References}

1. Alt, G.H.; Schertl, P. \& Koppl, A.- Journal of Organometallic Chemistry, 568, p.263 (1998). 
2. Meng, F.; Yu, G. \& Huang, B.- Journal of Polymer Science. Part A: Polymer Chemistry, 37, p.37 (1999).

3. Tian, J.; Wang; S.; Feng, Y.; Li, J. \& Collins, S.- Journal of Molecular Catalysis. A: Chemical, 144, p.137 (1999).

4. Pal, K.- International Polymer Science and Technology, 26, p. 57 (1999).

5. Leaversuch, R.D.- Modern Plastic Int., 7, p. 46 (1996).

6. Ewen, J.A.; Jones, R.L.; Razavi, A. \& Ferrara, J.D.J.Journal of the American Chemical Society, 110, p. 6255 (1992).

7. Bastos, Q.C.- "'Sistema de Catalisador Metalocênicos Binário para a Síntese de Polipropileno". Dissertação de Mestrado, Universidade do Rio de Janeiro, Brasil (2002).

8. Thomas, C. \& Mathias, P. - Macromolecules, 33, p. 9452 (2000).

9. Box, G.E.P.; Hunter, W.G \& Hunter, J.S.- "Statistics for experiments", John-Wiley, New York (1978).
10. Bastos, Q.C.; Moreira, S.C.; Rego, J.D. \& Marques, M.F.V.-"Syndiotactic polypropylene polymerization using different supported metallocene catalysts", in: Proceedings of $59^{\text {th }}$ Annual Technical Conference, $p$. 1683, Dallas-Texas, May (2001).

11. Fink, G.; Mülhaupt, R. \& Brintzinger, H. H.- "40 Years Ziegler Catalysts", Springer Verlag, Heidelberg (1995).

12. Marigo, A.; Marega, C. \& Zannetti, R.- Macromol.Rapid comm., 15, p. 225 (1994).

13. Marques, M.F.V.; Lopes, D.E.B. \& Rego, J.D.-“Isotactic polypropylene obtained by ethylene bis(1indenyl)zirconium dichloride and methylaluminoxane catalyst system", in: Anais do $14^{\circ}$ Congresso Brasileiro de Eng. e Ciência dos Materiais, São Pedro-SP, (2000).

14. Marques, M.F.V.; Junior, P.A.C.; Guimarães, M.J.C. \& Coutinho, F. M. B.- Polímeros: Ciência e Tecnologia, 3, p. 26 (1998).

Enviado: 02/06/04

Aprovado: 30/08/04 